\title{
Promoting Young Learners' Oral Skills in China
}

\author{
$\mathrm{Lu} \mathrm{Li}^{1, *}$ \\ ${ }^{1}$ School of Social Science and Public Policy, KING's College London, Stamford St, London SE1 9NH, England \\ ${ }^{*}$ Corresponding author. Email: lu.1.li@kcl.ac.uk
}

\begin{abstract}
Low oral competence has long been confused by Chinese English learners, even for young learners. It is approximately resulted by four reasons: limited English exposure, limited English learning time, a primary focus on learning individual words and limited opportunities to produce English. This article aims to improve the learning efficiency of the general Chinese context in the classroom. In order to improve the verbal ability of young learners, this article puts forward several suggestions from three aspects: formulaic language, interaction, and meaning negotiation strategies.
\end{abstract}

Keywords: Spoken language, Oral competence, Formulaic language, Interaction, TBLT, CL, Negotiation for meaning

\section{INTRODUCTION}

In an increasingly globalised world, non-Englishspeaking countries regard proficiency as essential for competent communication, long-term economic growth, as well as facilitating opportunities for young people [1]. Furthermore, several Asian countries, including China, South Korea, and Japan, are reforming their language education programmes, such as learning English to primary school students at an earlier age [2]. These changes have led to an expansion of English-language learning among young learners (YLs). YLs are characterised by particular language learning mechanisms, characteristics, and learning purposes, which have led to extensive discussions of language learning goals.

For example, Cameron emphasised the importance of a solid based in oral language foundation for YLs, which has received various consensus [3]. In China, although the communication skills of YLs are emphasized in elementary school, most people still have speaking difficulties. This article will start with a specific background in China. Following that, the researcher will discuss three of the most important aspects that Chinese YL teachers must consider to improve their oral skills, including formulaic language, interaction and meaning negotiation strategies. It will be concluded that, although teaching YLs English is an arduous task, after mastering some basic teaching knowledge, the verbal ability of YLs' can be effectively improved because children are gifted in language learning.

\section{THE SPECIFIC CONTEXT}

This study primarily focuses on Chinese English learners who are studying English in a language institution. They are between the ages of six and seven, in their first year of primary school. Despite having learned English in kindergarten for more than two years, their English proficiency level is deficient for three reasons. The first reason is that YLs can seldom be exposed to English or produce English except in English class, since English is learned as a foreign language in China. Secondly, some kindergartens and primary schools mainly focus on teaching vocabulary with ignorance of speaking English. Thirdly, the English learning time of Chinese YLs is minimal. As a result, even though they have a basic grasp of the English language, they cannot speak it fluently. Given the limited exposure to English and the limited learning time, the core principle of this article is to promote effectiveness in the classroom in terms of language use and interaction.

\section{PROMOTION THE USE OF FORUMULAIC LANGUAGE}

The traditional approach to learning languages has been to learn the words and then to learn how to combine them [4]. However, modern technology provides a new perspective for language production through the analysis of actual language corpora. Many studies have shown that a large part of spoken and written language is formulaic [4] [5]. Wray defines formulaic language as a "continuous or discontinuous sequence of words or other 
elements, which is or appears to be prefabricated: that is, it is stored and retrieved from memory as a whole when used, rather than subject to generation or language Syntax analysis"[6]. This represents single choices, bypassing controlled processing and short-term memory constraints, and thus dramatically reduces the burden of processing for the speaker and the listener [7]. In other words, formulaic language can be produced fluently and processed more rapidly when produced or understood. As a result, promoting formulaic language might be the most effective method to develop oral competence within a limited timeframe.

Although formulaic language acquisition is widely regarded as having significant benefits in the second language (L2) learning theory [8], few empirical studies have explored its benefits in English as a foreign language (EFL) setting, especially in a YL context [4]. The study Silva conducted revealed a close relationship between oral interaction and formulaic language in YL settings presenting illuminating insights for teachers [8]. He found that formulaic language can improve YLs' oral skills in both fluency and accuracy. Additionally, results of this study indicated that formulaic language can be effectively promote interaction, and that young learners felt more confident and motivated when speaking. The findings of Silva's study are persuasive, but more empirical research is still required in term of the use of formulaic language and YLs' oral proficiency [8].

There is a consensus that formulaic language can facilitate oral proficiency [4] [6] [9]. However, there is no reason to suppose that there are any differences between formulaic language and individual words in terms of learning process. In contrast, formulaic language acquisition is also incremental with its specific learning burden [9]. Nation states that there are three cognitive processes in remembering a word: noticing, retrieval, and creative use [10]. The same is true of formulaic language. According to Wood, formulaic language can be integrated into the classroom by focusing on it when dealing with input and interaction [11].

Concerning input, it is crucial to be exposed to authentic input in formulaic language acquisition [12]. Due to the lack of understanding of the social background of English learning in China, the teacher's speech seems to be the most common and often the only input, which may not be enough to obtain formulaic language. Therefore, it is suggested that teachers teach formulaic language, including collocation, idiom, and semi-fixed expression[4], because it is one of the main ways to cultivate attention[10]. Furthermore, explicit instruction can facilitate students' learning of formulaic language in a short period [4]. Resources such as songs and graded readers are excellent for teaching formulaic language explicitly since they often include repeated formulaic sequences [4]. As Bland states, song and stories offer formulaic input for language development and a vehicle for a range of activities.

In terms of interaction, it has been considered integral to facilitating the acquisition of formulaic language [11]. When learners are in interactions with the feature of negotiation for meaning, they can assist each other in negotiating complex or unfamiliar language. At the same time, formulaic sequences enable participants in achieving their communication goals [12]. The findings of Üstünbaş and Ortactepe support the argument that the number of formulaic languages used in child-child interactions is significantly related to their oral assessment scores in terms of accuracy and fluency [13]. In addition, Silva revealed that interaction could be facilitated by using formulaic language. In short, interaction can promote the acquisition of formula language; in turn, mastering formula language can also promote interaction.

In conclusion, YLs' oral competence can be facilitated by the acquisition of formulaic language. Formulaic language acquisition needs input, interaction, and instruction. This section has mentioned the importance of productive use of language and negotiation of meaning. In the next section, to ensure that YLS have sufficient opportunities to use language and negotiate meaning in the classroom effectively, researchers will focus on ensuring the effectiveness of facilitating interaction.

\section{FACILITATING CHILD-CHILD INTERACTION}

Along with the consensus that exposure to authentic input is one of the prerequisites for second language acquisition (SLA), the literature also shows interaction as an essential factor in SLA [12]. Long posited the interaction hypothesis in which conversation provides the best medium for developing language proficiency [14] [15]. During interactions, the learners utilize previous knowledge that they have acquired to achieve different communication goals. Studies have shown that learners who communicate more often achieve more significant improvements in oral proficiency than those who prefer to stay silent [16]. In line with the depth of processing hypothesis, the more times learners use a word, the greater the chances they will remember it. As such, teachers should facilitate a variety of oral communicative interactions among young learners to productively use language and significantly develop their oral skills, enabling them to communicate meaningfully in real-life social contexts.

In China, learners rarely can use English in their daily lives, so the classroom might be the only place where YLs can hear and speak English. Additionally, there is rare child-child interaction in traditional Chinese classrooms, and interaction is mostly between teachers 
and students in the form of question and answer, which is ineffective. In addition, a study conducted by LázaroIbarrola and Azplicueta-Martinez showed that learners have higher motivation and autonomy in child-child interactions than teacher-child interactions. Furthermore, learners use communication strategies more frequently in child-child interactions [17]. Thus, child-child interaction is beneficial for YLs in terms of language learning. The following pedagogical approaches will be recommended in order to engage all YLs in child-child interaction.

\subsection{Task-based Language Teaching (TBLT)}

TBLT is an extension of communicative language teaching (CLT), which has all the advantages of CLT and also avoid the deficiency of ignorance of linguistics forms [18] [19]. Firstly, it engages learners in real communication by providing comprehensible input for the acquisition process [20]. TBLT gives them real-life experiences of communication, which will benefit them in their future life. In addition, it enables the learners to use accurate language during accuracy-oriented activities [18]. Furthermore, TBLT provides learners with various challenges with information gaps, which motivates them and enhances their learning experience [21]. In terms of TBLT's potential to improve YLs' oral skills, an empirical research study conducted by Zulianti amongst Year Two students revealed surprising results [22]. By testing learners' speaking ability to retell a text, he assessed learners' pronunciation, grammar, vocabulary, and fluency. As a result of using TBLT four times, students received a post-test mean score of 107.181, a considerable improvement over their pre-test (59.979) [22].

Despite TBLT's features of meaning-based interaction and target language use that can help to promote effective interaction, its implementation is complex, particularly in the YL classroom. For example, YLs in the researcher's classroom has a deficient proficiency level; consequently, they cannot interact freely. This echoes Klapper's criticism that TBLT processes limitations for beginners due to its insufficient support in language forms [20]. However, from a different perspective, Lázaro-Ibarrola and AzpilicuetaMartínez [23] emphasize that child-child interaction is possible and beneficial regardless of the learner's language level. Although these two views seem to be convincing to some extent, teachers must choose a method based on learners' proficiency and needs analysis [3] [19]. In summary, TBLT is conducive to the language learning of YLs. Finding a balance and making appropriate adjustments will make it more suitable for different contexts.

\subsection{Cooperative Learning}

$\mathrm{CL}$ is an instructional approach that involves students working in small groups with specific goals [24]. Students have a wide range of opportunities to use the target language in CL, including asking questions, giving answers, suggesting ideas and critically reflecting on others' ideas. Various CL activities can develop language skills, such as puzzles, thinking/matching/sharing, and round tables/round-robins. Several recent studies have been conducted on the effects of $\mathrm{CL}$ on learner achievement in various aspects [24] [25] [26]. Some studies have also shown that it promotes the development of YL oral skills [27] [28].

CL provides significant value to promoting young learners' cognitive and oral competence and to facilitating learners' social and emotional development [24]. In addition, learning how to cooperate with others is one of the crucial educational objectives [29]. Hence, $\mathrm{CL}$ is strongly recommended for YL teachers. However, the implementation of CL might be challenging for teachers because there is a considerable amount of preparation and effort necessary, as well as an ability to manage time, especially in the lower level of primary school [30]. This echoes Kutnick, Ota and Berdondini's statement that the difficulty of implementing CL should not be underestimated [31]. Some CL approaches include several steps which might be complex for YLs to implement. Therefore, typical stages of applying tasks in the classroom are significant, such as selecting a clear objective, dividing the objective into steps, modelling, providing scaffolding, and providing assistance.

In conclusion, since English learning time and opportunities are limited, teachers need to select the most effective and appropriate approaches and activities for YLs. Further, teachers should consider approaches to improve learning effectiveness and develop language skills rather than pursuing pure approaches, such as a robust version of TBLT. Fundamentally, teachers need to adjust approaches and activities according to learners' interests and their particular context.

\section{EXPLICIT INSTRUCTION OF COMMUNICATION STRATEGIES}

The interaction hypothesis holds that learners often experience communication problems during interactions and they negotiate to attain an attainable degree of understanding [14] [15]. In such negotiations for meaning, the learners' output is modified, which results in enriching opportunities for language learning by integrating "input, internal learner capacities, particularly selective attention, and output in productive ways." [15]. Moreover, the strategy of meaning negotiation also requires more attention. Long initially proposed the three strategies: clarification requests, confirmation checks, and understanding checks [14]. Additionally, repetitions, 
recasts, explicit corrections, and L1 use are often involved in the analysis of negotiations. Research emphasizes the importance of various scholars in negotiating to mean, and most involve the experience of adult students with English as a second language (ESL). However, few studies have examined child interaction with English speakers in EFL contexts [32]. In terms of whether negotiating for meaning occurs during YLs' interaction, Oliver's studies have demonstrated that children do negotiate meaning during interaction with partners of the same age. They employ communicative strategies comparable to those used by adults, although to a lesser extent [32]. However, LáZaro-Ibarrola and Azpilicueta-Martínez found that the negotiation of EFL YLs was far less than that of ESL adults and YLs [23]. Teachers should provide some strategic guidance to YLs because they lack communication strategies and can participate in all dialogues smoothly. Additionally, teachers should bear in mind that they have the responsibility to carefully monitor the way learners speak to find and solve problems as soon as possible.

\section{CONCLUSION}

This essay first provides a general context in China and information on a specific group of YLs. Given the scarcity of English exposure and limited learning time, three essential suggestions that teachers need to consider were discussed to promote their oral proficiency based on the core principle of effectiveness facilitation. The first aspect is to use formulaic language to speed up learning a language and promote fluency. The second aspect involves using TBLT and CL to promote effective interaction because these methods can provide YL with sufficient opportunities to interact with children through meaning-based products. The third aspect relates to the necessity to explicitly teach negotiation for strategies because mastering those strategies can facilitate negotiations during child-child interactions, leading to L2 learning. Learning a foreign language is a long-term task that requires teachers' substantial support and assistance by providing a language model and promoting students' motivation and self-confidence.

\section{AUTHORS' CONTRIBUTIONS}

This essay is completely and independently conducted by the author $\mathrm{Lu} \mathrm{Li}$.

\section{ACKNOWLEDGMENTS}

The title "ACKNOWLEDGMENTS" should be in all caps and should be placed above the references. The references should be consistent within the article and follow the same style. List all the references with full details.

\section{REFERENCES}

[1] J. Enever, Policy, in: J. Enever (Eds), ELLiE: Early language learning in Europe, British Council, London, 2011, pp. 23-43.

[2] V.A. Murphy, Second Language Learning in the Early School Years: Trends and Contexts-Oxford Applied Linguistics, Oxford University Press, Oxford, 2014.

[3] L. Cameron, Teaching languages to young learners, Cambridge University Press, Cambridge, 2001.

[4] S. Kersten, Language Development in Young Learners: The Role of Formulaic Language, in: J. Bland (Eds), Teaching English to young learners : Critical issues in language teaching with 3-12 year olds, Bloomsbury Academic, New York, 2015, pp. 129-145.

DOI: https://doi.org/10.5040/9781474257145.ch-008

[5] B. Erman, B. Warren, The idiom principle and the open choice principle, Text \& Talk 20(1) (2000) 2962.

DOI:

https://doi.org/10.1515/text.1.2000.20.1.29

[6] A. Wray, Formulaic language and the lexicon, Cambridge University Press, 2005.

[7] J. Sinclair, Corpus, concordance, collocation, Oxford University Press, 1991.

[8] L.G.D. Silva, Formulaic language sequences and Oral Interaction in the Primary English Classroom, Unpublished doctoral dissertation, Universidade Nova de Lisboa, 2020.

[9] N. Schmitt, Formulaic language and collocation, in: C. Chappelle (Eds.), The Encyclopedia of Applied Linguistics, Blackwell, New York, 2012, pp. 1-10. DOI:

https://doi.org/10.1002/9781405198431.wbeal0433

[10] I.S.P. Nation, Learning Vocabulary in Another Language, Cambridge University Press, 2013.

[11] D. Wood, Formulaic language acquisition and production: Implications for teaching, TESL Canada Journal 20(1) (2002) 1-15. DOI: https://doi.org/10.18806/tesl.v20i1.935

[12] F. Meunier, Formulaic language and language teaching, Annual Review of Applied Linguistics 32 (2012) 111-129. DOI: https://doi.org/10.1017/s0267190512000128

[13] Ü. Üstünbaş, D. Ortactepe, EFL learners' use of formulaic language in oral assessments: A study on fluency and proficiency, Hacettepe Üniversitesi Eğitim Fakültesi Dergisi 31(3) (2016) 578-592. DOI: https://doi.org/10.16986/huje.2016017558 
[14] M.H. Long, Native speaker/non-native speaker conversation and the negotiation of comprehensible input1, Applied Linguistics 4(2) (1983) 126-141. DOI: https://doi.org/10.1093/applin/4.2.126

[15] M.H. Long, The role of the linguistic environment in second language acquisition, in: W. Ritchie, T. Bhatia (Eds), Handbook of Second Language Acquisition, Academic Press, San Diego, 1996, pp. 413-468. DOI: https://doi.org/10.1016/b978012589042-7/50015-3

[16] E. Namaziandost, A. Hashemifardnia, S. Shafiee, The impact of opinion- gap, reasoning-gap, and information-gap tasks on EFL learners' speaking fluency, Cogent Social Science 5(1) (2019) 1-16. DOI: https://doi.org/10.1080/23311886.2019.1630150

[17] A. Lázaro-Ibarrola, R. Azplicueta-Martinez, Spotting the Differences between Child-Child and Child-Adult Interactions: Evidence from Spanish EFL Learners at Low Levels of Proficiency, in: J. Rokita-Jaâskow, M. Ellis (Eds), Early Instructed Second Language Acquisition, Multilingual Matters, Bristol, 2019, pp. 80-105. DOI: https://doi.org/10.21832/9781788922517-008

[18] M. East, Taking communication to task - again: what difference does a decade make?, Language Learning Journal 43(1) (2015) 6-19. DOI: https://doi.org/10.1080/09571736.2012.723729

[19] P. Lightbown, N. Spada, How Languages are Learned, Oxford University Press, 2013.

[20] J. Klapper, Taking communication to task? A critical review of recent trends in language teaching, Language Learning Journal 27(1) (2003) 33-42. DOI: https://doi.org/10.1080/09571730385200061

[21] M. East, Task-Based Language Teaching From the Teachers' Perspective : Insights From New Zealand, John Benjamins Publishing Company, 2012.

[22] P.O. Zulianti, The Effect Of Task Based Language Teaching (TBLT) Towards Student' Speaking Ability Of Second Grade Student At MTSN 3 KOTA PEKANBARU, Unpublished doctoral dissertation, Universitas Islam Riau, 2019.

[23] A. Lázaro-Ibarrola, R. Azpilicueta-Martínez, Investigating negotiation of meaning in $\mathrm{EFL}$ children with very low levels of proficiency, International Journal of English Studies 15(1) (2015) 1-21. DOI: https://doi.org/10.6018/ijes/2015/1/203751

[24] R.E. Slavin, E.A. Hurley, A. Chamberlain, Cooperative learning and achievement: Theory and research, in: W.M. Reynolds, G.E. Miller (Eds),
Handbook of psychology: Educational psychology: Vol. 7, Wiley, New York, 2003, pp. 177-198. DOI: https://doi.org/10.1002/9781118133880.hop207008

[25] S. Sharan, Z. Ackerman, R. Hertz-Lazarowitz, Academic achievement of elementary school children in small-group versus whole-class instruction, The Journal of Experimental Education 48(2) (1979) 125-129. DOI: https://doi.org/10.1080/00220973.1979.11011725

[26] R.E. Slavin, When does cooperative learning increase student achievement?, Psychological Bulletin 94(3) (1983) 429-445. DOI: https://doi.org/10.1037/0033-2909.94.3.429

[27] I. M. P. Maldonado, L. M. R. Banoy, E.S. Quinche, Ii.Y. Francés, Role of cooperative learning strategies in the development of 5th graders' speaking skills at George Washington school, Universidad De La Salle, 2011.

[28] F. Talebi, A. Sobhani, The impacts of cooperative learning on oral proficiency, Mediterranean Journal of Social Sciences 3(3) (2012) 75-75.

[29] B. Barron, When smart groups fail, The Journal of the Learning Sciences 12(3) (2003) 307-359. DOI: https://doi.org/10.1207/s15327809j1s1203_1

[30] P. Blatchford, E. Baines, C. Rubie-Davies, P. Bassett, A. Chowne, The effect of a new approach to group work on pupil-pupil and teacher-pupil interactions, Journal of Educational Psychology 98(4) (2006) 750-765. DOI: https://doi.org/10.1037/0022-0663.98.4.750

[31] P. Kutnick, C. Ota, 1. Berdondini, Improving the effects of group working in classrooms with young school-aged children: Facilitating attainment, interaction and classroom activity, Learning and Instruction 18(1) (2008) 83-95. DOI: https://doi.org/10.1016/j.learninstruc.2006.12.002

[32] R. Oliver, How young is too young? Investigating negotiation of meaning and feedback in children aged five to seven years, in: A. Mackey, C. Polio (Eds), Multiple Perspectives on Interaction. Second Language Research in Honor of Susan M. Gass, Routledge, New York, 2009, pp. 135-156. 